\title{
Pearls
}

\section{Pearls: Wrong-level Surgery Prevention}

\author{
Charles A. Reitman MD
}

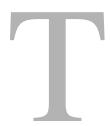
he Sign Your Site initiative and the Pause Before Making Incision policies are great ways to prevent wrong-site surgery [2]. However, for spine surgeons, these

Note from the Editor-in-Chief: We are pleased to introduce the next installment of "Pearls," a new column in Clinical Orthopaedics and Related Research ${ }^{\mathbb{R}}$. In this column, distinguished surgeons, scientists, or scholars share surgical or professional tips they use to help surmount important or interesting problems. We welcome reader feedback on all of our columns and articles; please send your comments to eic@clinorthop.org.

The author certifies that he, or a member of his immediate family, has no funding or commercial associations (eg, consultancies, stock ownership, equity interest, patent/ licensing arrangements, etc.) that might pose a conflict of interest in connection with the submitted article.

All ICMJE Conflict of Interest Forms for authors and Clinical Orthopaedics and Related Research ${ }^{\circledR}$ editors and board members are on file with the publication and can be viewed on request.

The opinions expressed are those of the writers, and do not reflect the opinion or policy of $C O R R^{\circledR}$ or The Association of Bone and Joint Surgeons ${ }^{\mathbb{R}}$.

\footnotetext{
C. A. Reitman MD ( $\square)$

Department of Orthopaedics, Medical

University of South Carolina, 96

Jonathan Lucas Street, 708 CSB,

Charleston, SC 29425, USA

e-mail: reitman@musc.edu
}

efforts do little to prevent wrong-level spine surgery.

Several factors can contribute to wrong-level spine surgery, including morbid obesity, thoracic location, presence of multiple lesions, transitional anatomy, congenital anomaly, age, and diminished mineralization of bone [4]. While some of these factors can be overcome with careful preparation, in those patients where difficulty can be predicted, preoperative localization is vital. This can be done in the radiology interventional suite with accurate image guidance. These approaches can save considerable time, minimize uncertainty during surgery, and most importantly, help prevent wrong-level surgery.

Several localization techniques have been described and can be generally divided into those that place markers in the soft tissue, and those that place them in the bone itself $[1,3,5-8]$. In these challenging patients, I firmly believe that there is no role for soft-tissue markers. Fixed markers in bone are ideal, as they cannot be altered with initial exposure and remain visible during the critical parts of the procedure.

For difficult procedures, it is not uncommon to repeatedly check proper levels, and markers in bone offer a durable localizer. There are several options, including wires or screws that can be deployed percutaneously and placed in a variety of structures. We prefer angiography coil at our institution. They are simple, fast, easily visible, and can be placed into the pedicle with a single-step deployment under image guidance. I prefer the pedicle for placement site. This provides a secure and reliable anchor site, and it is straightforward to interpret during the operative procedure as compared to a spinous process, which can have a variable relationship to the intended vertebral body or disc space.

The desired level is identified both by the reported level in the imaging report,

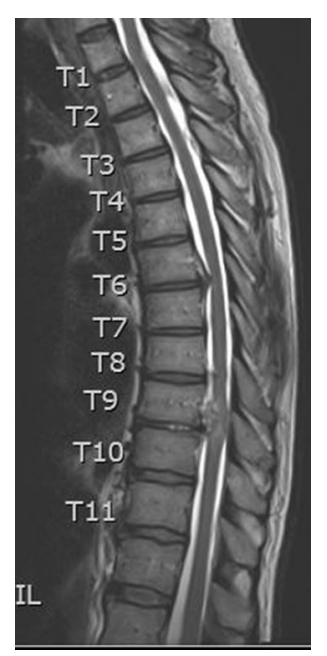

Fig. 1 An axial MR image shows a compressive lesion. 


\section{Pearls}

and descriptively by the level of the lesion (Fig. 1). I make a point of communicating directly with the interventional radiologist, as well. The marker can be placed preoperatively with sedation, but more commonly, this procedure is coordinated so that the patient is anesthetized in radiology, the marker is placed under general anesthesia, and then the patient is taken directly to surgery (Fig. 2). The marker is easy to see on both AP (Fig. 3A) and lateral images (Fig. 3B), and it remains visible during decompression and/or instrumentation if needed (Fig. 3C).

Fig. 2A-D (A) AP and (B)

lateral radiographs with trochars placed prior to deployment of coil are shown. (C) AP and (D) lateral radiographs with coil positioned in the pedicle are shown.
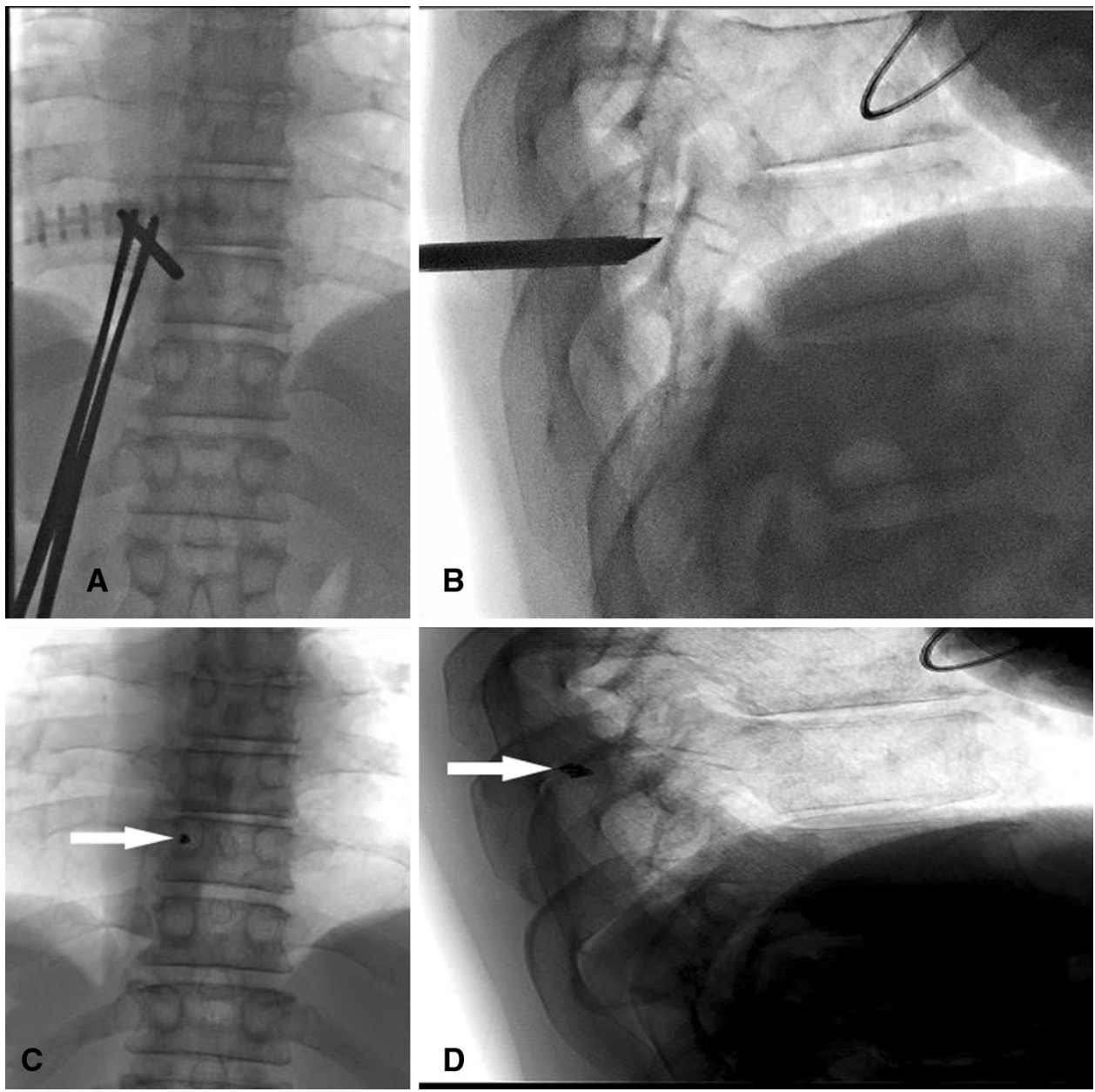


\section{Pearls}

Fig. 3A-C (A) AP and (B) lateral intraoperative marker films are shown. (C) The AP radiograph shows

intraoperative placement of pedicle markers.
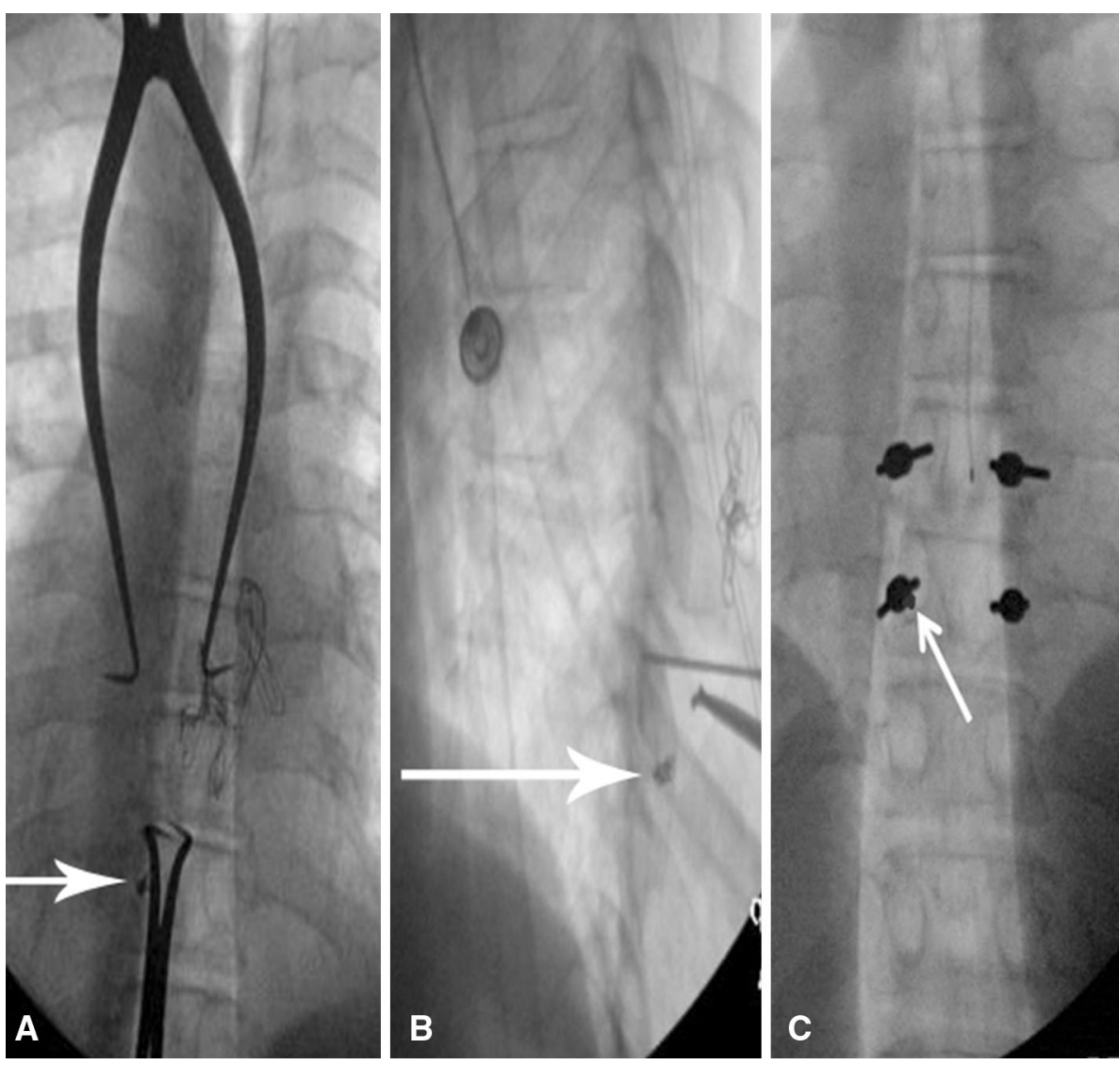

3. Hsu W, Sciubba DM, Sasson AD, Khavkin Y, Wolinsky J-P, Gailloud P, Gokasalan Z, Murphy K. Intraoperative localization of thoracic spine level with preoperative percutaneous placement of intravertebral polymethylmethacralate. $J$ Spinal Disorders Tech. 2008;21:72-75.

4. Palumbo M, Bianco AJ, Esmende S, Daniels AH. Wrong site surgery. $J$
Amer Academy Orthop Surg. 2013;21: 312-320.

5. Paolini S, Ciappetta $\mathrm{P}$, Mossori $\mathrm{P}$, Raco A, Delfini R. Spinous process marking: A reliable method for preoperative surface localization of intradural lesions of the high thoracic spine. $B r \quad J$ Neurosurg. 2005;19: 74-76. 
6. Rosahl SK, Gharabaghi A, Liebig T, Feste CD, Tatagiba M, Samii M. Skin markers for surgical planning for intradural lesions of the thoracic spine: Technical note. Surg Neurol. 2002;58:346-348.
7. Upadhyaya CD, Wu JC, Chin CT, Balamurali G, Mummaneni PV. Avoidance of wrong-level thoracic spine surgery: Intraoperative localization with preoperative percutaneous fiducial screw placement. $J$ Neurosurg Spine. 2012:16:280-284.
8. Young RM, Prasad V, Wind JJ, Olan W, Caputy AJ. Novel technique for preoperative pedicle localization in spinal surgery with challenging anatomy. J Neurosurg Spine. 2014;20: 400-403. 